\title{
Influence of microcirculation load on FFR in coronary artery stenosis model
}



Hongzeng $\mathrm{Xu}$, Jing Liu, Donghui Zhou and Yuanzhe Jin ${ }^{*}$

\begin{abstract}
Background: The coronary artery hemodynamics are impacted by both the macrocirculation and microcirculation. Whether microcirculation load impact the functional assessment of a coronary artery stenosis is unknown. The purpose of this study is to investigate the effect of porous media of the microcirculation on fractional flow reserve (FFR) in stenotic coronary artery model.

Methods: A three dimensional computational simulation of blood flow in coronary artery symmetric stenotic model was constructed. The computational fluid dynamics (CFD) model was developed with Fluent 16.0. Blood was modeled as a shear thinning, non-Newtonian fluid with the Carreau model. A seepage outlet boundary condition and transient inlet conditions were imposed on the model. Coronary physiologica diagnostic parameter such as pressure, velocity and fractional flow reserve (FFR) were investigated in the model and compared with the microcirculation load (ML) and constant pressure load (PL) condition.

Results: The present study showed the different hemodynamics in the ML and PL condition. The pre-stenotic pressure is almost the same in the two model. However the pressure in the post-stenotic artery domain is much lower in the PL model. The fluctuation range of the pressures is much higher in ML model than those in PL model. The velocity flow was more steady and lower in the ML model. For the PL model with $75 \%$ artery stenosis the FFR was 0.776 , while for the ML model with the same stenosis, the FFR was 0.813 .
\end{abstract}

Conclusions: This study provides evidence that FFR increased in the presentation of ML condition. There is a strong hemodynamic effect of microcirculation on coronary artery stenosis.

Keywords: Coronary artery disease, Microcirculation, Hemodynamics, FFR

\section{Background}

Coronary artery disease (CAD) are characterized with epicardial stenosis and microcirculation dysfunction. And the coronary artery hemodynamics are affected both by the epicardial stenotic coronary artery impede and microcirculation load. Regulation of coronary blood flow is quite complex [1], epicardial stenosis severity and microcirculatory resistance may affect each other [2, 3]. However, the complex interrelationship between the coronary microcirculation and the epicardial coronary arteries contributing

\footnotetext{
*Correspondence: yzjin@cmu.edu.cn

Department of Cardiology, The fourth Affiliated Hospital of China Medical University, No. 4, Chongshan Road, Huanggu District, Shenyang 110032, China
}

to the coronary artery hemodynamics remains poorly understood and is controversial [4]. Some recent studies have suggested that microvascular resistance at maximal vasodilation will increase when the severity of epicardial disease increases [5]. While other studies showed that coronary microcirculatory resistance is independent of epicardial coronary artery stenosis [6], and coronary microcirculatory resistance is not influenced by the epicardial stenosis severity [7]. Now, epicardial coronary artery stenosis is regarded to exert their pathological role mainly through a limitation on maximal flow capacity in the distal vascular bed. However, how the distal microcirculation bed impact the hemodynamics of coronary artery was unknown. It's believed that the microcirculation load has a

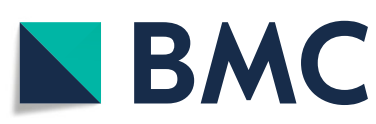

(c) The Author(s). 2020 Open Access This article is licensed under a Creative Commons Attribution 4.0 International License, which permits use, sharing, adaptation, distribution and reproduction in any medium or format, as long as you give appropriate credit to the original author(s) and the source, provide a link to the Creative Commons licence, and indicate if changes were made. The images or other third party material in this article are included in the article's Creative Commons licence, unless indicated otherwise in a credit line to the material. If material is not included in the article's Creative Commons licence and your intended use is not permitted by statutory regulation or exceeds the permitted use, you will need to obtain permission directly from the copyright holder. To view a copy of this licence, visit http://creativecommons.org/licenses/by/4.0/ The Creative Commons Public Domain Dedication waiver (http://creativecommons.org/publicdomain/zero/1.0/) applies to the data made available in this article, unless otherwise stated in a credit line to the data. 
great influence on the bloodstream, and has important influence on various phenomena in the flow field [8]. Moreover, such microvascular alterations with altered microvascular resistance may partly obscure Fractional flow reserve (FFR) measurements $[9,10]$. Therefore, a complete hemodynamic model is needed to take into account the influence of microcirculation load effect.

Computational fluid dynamics (CFD) simulation has been widely used to study the hemodynamic parameters in coronary arteries due to the limitation of in vivo measurements [11]. FFR is currently used as a gold standard for the assessment of functional significance of stenosis severity and is applied for guiding cardiovascular intervention. Recently, the CFD approach has been used to determine the FFR from the clinical medical image or numerical simulation. In these CFD hemodynamics simulations, boundary conditions are vital for obtaining accurate flow patterns. Hewever, there are lack of numerical simulation studies to determine FFR and hemodynamic changes due to microcirculation impedance outlet boundary conditions.

The resistance offered by microcirculation to blood flow can be conceived as the resistance encountered by fluid passing through porous medium [12]. It has been established that the flow in microcirculation can be simulated by using a porous flow model [13, 14]. Based on seepage theory [15], the seepage flow could be specified as a boundary condition which shows that the resistance caused by the seepage condition in microcirculation. To obtain the large and complex microvascular anatomy is difficult, a porous medium model may replicate the downstream capillary structures, which can supply the essential characteristics of the seepage flow in microcirculation. Therefore, a load of porous media seepage could be imposed at the outlet of the artery stenosis model to simulate the microcirculation. In this study, a 3D computational coronary stenotic artery model with outlet condition of microcirculation load (ML) and constant pressure load (PL) was constructed. The purpose of this study is to investigate the effect of porous media of the microcirculation on coronary artery stenosis hemodynamics.

\section{Methods}

\section{Geometry model}

In this work, the artery model was considered as a symmetric stenotic geometry as shown in Fig. 1. Stenotic regions consist of converging (of length $l_{c}=1.5 \mathrm{~mm}$ ), throat (of radius $r_{\mathrm{s}}=0.7 \mathrm{~mm}$ and length $\mathrm{l}_{\mathrm{s}}=1.2 \mathrm{~mm}$ ) and diverging (of length $l_{d}=3 \mathrm{~mm}$ ) sections which was considered as trapezoidal. Moreover, proximal and distal radii are assumed to be identical $\left(r_{p}=r_{d}=1.4 \mathrm{~mm}\right)$. Artery area stenosis (AS) percentage was $75 \%$, which was defined as:

$$
\frac{r_{p}^{2}-r_{s}^{2}}{r_{p}^{2}} \times 100 \%
$$

\section{Computational blood flow model}

It was assumed that the flow of blood in the coronary artery is incompressible and governed by the NavierStokes equations

$$
\rho\left(\frac{\partial_{u}}{\partial_{t}}+u \cdot \nabla u\right)=-\nabla p+\nabla \cdot T
$$

and the continuity equation for incompressible flow is

$$
\nabla \cdot u=0
$$

Here $u$ is the three dimensional velocity vector, $\mathrm{t}$ the time, $\rho$ the blood density, $p$ the pressure and $T$ the stress tensor. The flow was set as laminar with a density of $1060 \mathrm{~kg} / \mathrm{m}^{3}$.

As is well known, the viscoelasticity and shear thinning of the blood [16] are closely relevant to its microscopic features, such as deformation, aggregation and alignment of the red blood cells. In this study, the blood flow was modeled to be homogenous and non-Newtonian, and we used the Carreau model

$$
\mu=\mu_{\infty}+\left(\mu_{0}-\mu_{\infty}\right)\left[1+(\lambda \gamma)^{2}\right]^{(n-1) / 2}
$$

where $\mu$ is the dynamic viscosity, $\mu_{0}$ and $\mu_{\infty}$ are the viscosity as the shear rate goes to infinity and zero, $\gamma$ is the shear rate, $\lambda$ is the time constant and $n$ is the power-law index. All values were taken from the literature, $\mu_{0}=$

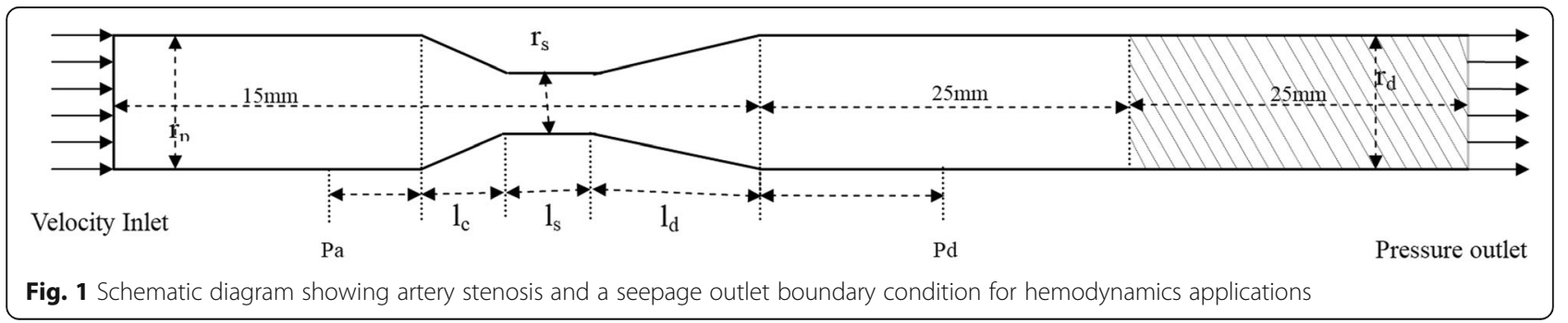


$0.0560 \mathrm{~Pa} \cdot \mathrm{S}, \mu_{\infty}=0.00345 \mathrm{~Pa} \cdot \mathrm{S}, \lambda=3.313 \mathrm{~s}$ and $n=0.3568$ [17].

\section{Microcirculation domain}

Accounting the aspect of circulation system structure, a complete hemodynamic model requires consideration of the microcirculation load effect. Microcirculation is considered as a porous medium. In this study, the outlet impedance, as a seepage boundary condition, is provided by the flow in the microcirculation porous zone. We set the porosity of the microcirculation to $\phi=0.5$ [18]. The following empirical equation is adopted to compute the microcirculation zone permeability, which is determined by the porosity:

$$
\mathrm{k}=\frac{d^{2} \phi^{3}}{180(1-\phi)^{2}}
$$

where $\mathrm{d}$ is the diameter of the microvessel, and here we set $\mathrm{d}=100 \mu \mathrm{m}$ following the literature [12]. The governing equations in the microcirculation zone are determined as follows:

$$
\begin{aligned}
\rho\left(\frac{\partial_{(\phi u)}}{\partial_{t}}+u \cdot \nabla(\phi u)\right)= & -\nabla(\phi p)+\nabla \\
& \cdot(\phi T)-\frac{\phi^{2} \eta}{k} u
\end{aligned}
$$

$$
\nabla \cdot u=0
$$

\section{Boundary conditions and microcirculation domain}

As shown in Fig. 2, a transient time-dependent velocity profile of a typical coronary artery was applied at the inlet [19]. The maximum velocity was $0.46 \mathrm{~m} / \mathrm{s}$, the average velocity was $0.28 \mathrm{~m} / \mathrm{s}$ and the minimum velocity was $0.13 \mathrm{~m} / \mathrm{s}$. Accordingly, in the example of normal physiology, the heart rate was $75 / \mathrm{min}$ and the period of the flow waveform is $0.8 \mathrm{~s}$. Both ML and PL cases were solved with the same inlet boundary conditions. The outlet condition was pressure free, and was set as the distal venules pressure 3333 Pascal ( $\mathrm{Pa}, 25 \mathrm{mmHg}$ ) for the PL case $[20,21]$ and $0 \mathrm{~Pa}$ for the ML case. While in the ML cases the microcirculation zone is coupled at the outlet. We assume that the vessel walls are rigid and all velocity components were set to zero at the wall according to no-slip condition.

\section{Numerical methodology}

The computational domains were initially meshed with hexahedral and tetrahedral elements. The total number of elements vary from 200,000 to 295,000 for both ML and PL models. Computational simulations were performed with Fluent 16.0 (Ansys Inc., Canonsburg, USA). The transient flow analysis was run for 247 time steps (0.0032 s per time step) representing pulsatile flow with each time step converging to a residual target of $1 \times 10^{-5}$.

\section{FFR calculation}

FFR is the well-studied physiological parameter to guide coronary revascularization decision in clinical practice.

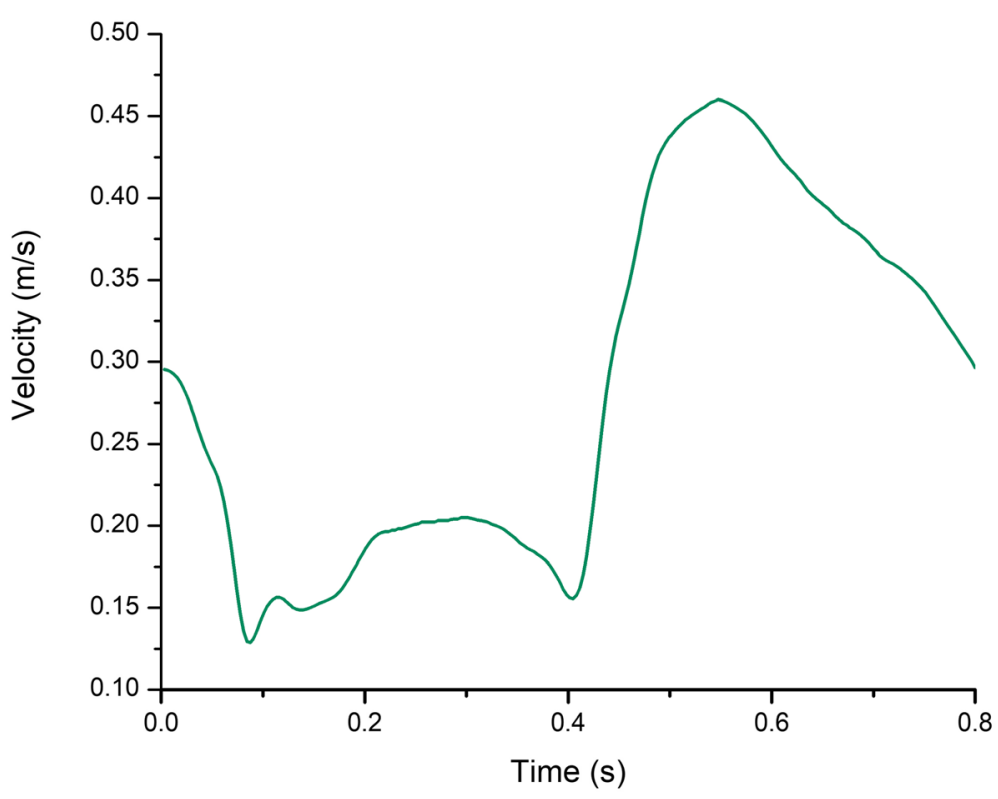

Fig. 2 The inlet velocity profile 
FFR is defined as the approximate ratio of distal coronary pressure to aortic pressure [22].

$$
\mathrm{FFR}=\frac{\tilde{\mathrm{P}}_{d}-\mathrm{P}_{v}}{\tilde{\mathrm{P}}_{a}-\mathrm{P}_{v}}
$$

where $\tilde{\mathrm{P}}_{a}$ is defined as the time averaged aortic pressure, $\tilde{\mathrm{P}}_{d}$ is the time averaged distal stenotic pressure measured at the end of flow reversal occurring and $\mathrm{P}_{\mathrm{v}}$ is the venous pressure which is assumed to be $0 \mathrm{mmHg}$.

\section{Results}

In both ML and PL models, the pressure and velocity distribution was simulated and FFR was analyzed.

\section{Pressures profile at different models}

Fig. 3 depicts the pressure distributions before and after stenosis of the artery zone under the microcirculation seepage and pressure outlet boundary condition. The pressure profile at the both sides of the stenosis at the artery zone are almost identical with the $\mathrm{ML}$ and $\mathrm{PL}$ conditions. The average of pre-stenotic pressure $\left(\tilde{\mathrm{P}}_{a}=\right.$ $4331 \mathrm{~Pa})$ and post-stenotic pressure $\left(\tilde{\mathrm{P}}_{d}=3522 \mathrm{~Pa}\right)$ in the ML model were higher than those $\left(\tilde{\mathrm{P}}_{a}=3611 \mathrm{~Pa}, \tilde{\mathrm{P}}_{d}=\right.$ $2805 \mathrm{~Pa}$ ) in the PL model.

As shown in Table 1, a large pressure drop occurs across the stenosis. The absolute values of the pressure drops across the stenosis were similar in the two models. However, the fluctuation range of the pressures varied with different boundary conditions. In the ML model, the fluctuation range of the pressures were higher than those in PL model.

\section{Velocity profile at different models}

Fig. 4 plots the different velocities in the two models of the artery zone. The time-dependent velocities in the artery zone with ML and PL condition are similar and resemble the velocity profiles imposed on the inlet. It shows that velocities in post-stenotic domain are more larger than the pre-stenotic domain in the two model because of the artery stenosis effect. While in the poststenotic artery zone, it is found that the velocities in the PL model are higher than those in the ML model. Clearly, the flow is impeded by the artery stenosis so that high flow velocities are produced to maintain the blood supply.

As shown in Fig. 4, the velocity distributions in the microcirculation zone are similar to those in other artery zone. However, the velocities in the microcirculation zone in ML model are much lower than the PL condition model. We know that the diameter of the microvessels is less than $300 \mu \mathrm{m}$ [23], so the corresponding velocities should be very low. In the ML model the waveform of the blood flow is more regular than that in the PL model, maybe the microcirculation porous media has a filtering effect on the circulation. Although the blood flow entering from the larger arteries is pulsatile, the flow in microcirculation is tend to be steady because of the repelling the pulsations by the capillaries.

\section{FFR calculation}

After obtained the averaged pressure drop $\Delta \tilde{\mathrm{P}}$ and the averaged pressure proximal to stenosis $\tilde{\mathrm{P}}_{a}$ from our computational study, FFR $\left(=\tilde{\mathrm{P}}_{d} / \tilde{\mathrm{P}}_{a}=1-\Delta \tilde{\mathrm{P}} / \tilde{\mathrm{P}}_{a}\right)$ was calculated. The FFR for the PL model was 0.776, while the FFR for the ML model was 0.813. The results showed that with the presence of microvasculature
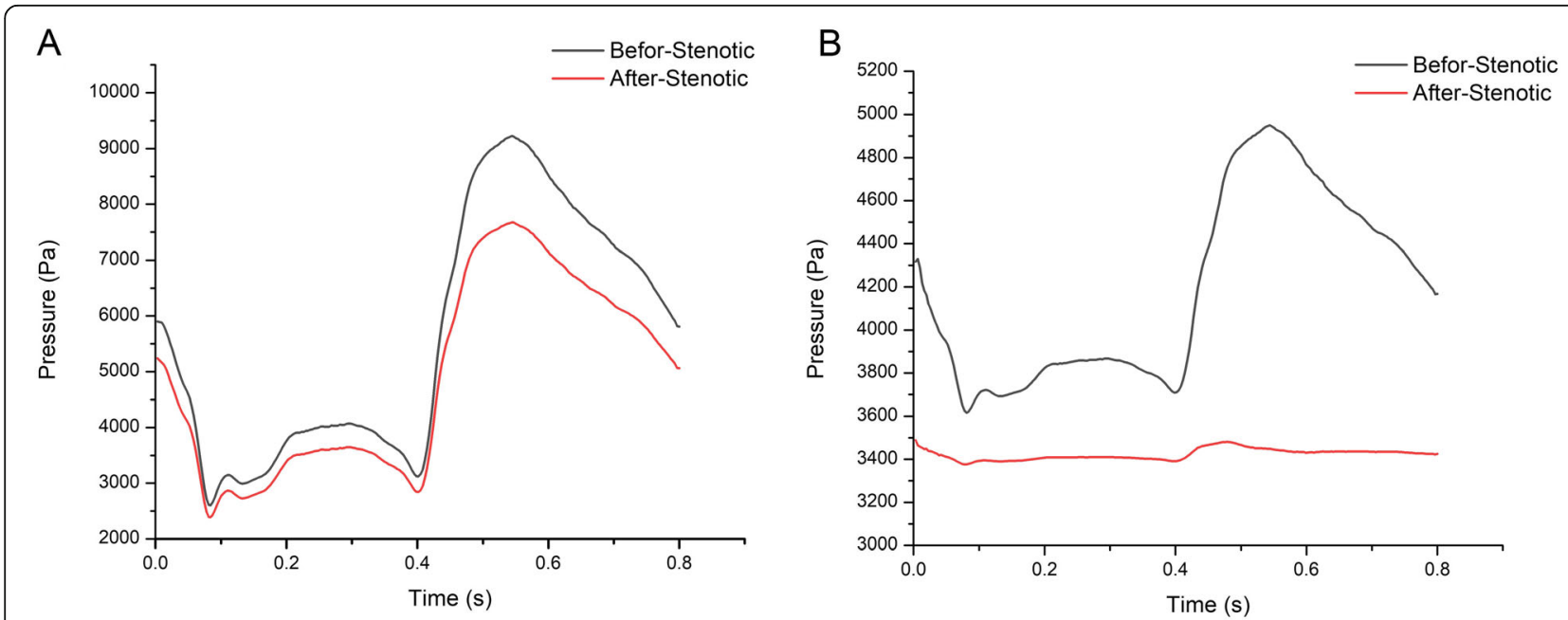

Fig. 3 Pressure profiles in the artery zone. a Pressure profiles in the ML model. b Pressure profiles in the PL model 
Table 1 The pressure difference in the artery zone and FFR calculation under the two outlet boundary conditions

\begin{tabular}{|c|c|c|c|c|c|c|c|c|}
\hline \multirow[t]{2}{*}{ Outlet } & \multicolumn{2}{|c|}{$\begin{array}{l}\text { The peak } \\
\text { Pressure }(\mathrm{Pa})\end{array}$} & \multicolumn{2}{|c|}{$\begin{array}{l}\text { The low } \\
\text { pressure }(\mathrm{Pa})\end{array}$} & \multicolumn{2}{|c|}{ Fluctuation range $(\mathrm{Pa})$} & \multirow[t]{2}{*}{ FFR } & \multirow[t]{2}{*}{$\mathrm{AS}(\%$} \\
\hline & $P_{a}$ & $P_{d}$ & $P_{a}$ & $P_{d}$ & $\mathrm{P}_{\mathrm{a}}(\%)$ & $P_{d}(\%)$ & & \\
\hline Microcirculation Seepage Load & 7170 & 5480 & 1980 & 1760 & $5190(72.4 \%)$ & $3720(67.9 \%)$ & 0.813 & $75 \%$ \\
\hline Pressure Load & 4540 & 2870 & 2960 & 2740 & $1580(34.8 \%)$ & $130(4.53 \%)$ & 0.776 & $75 \%$ \\
\hline
\end{tabular}

FFR Fractional flow researve, $P a$ Pressure at the aortic stenosis, $P d$ Pressure distal to the coronary stenosis, AS Area stenosis

resistance, blood flow through the fixed stenosis will decrease, and FFR will increase. So the FFR value was impact obviously by the microcirculation upload condition.

\section{Discussion}

In the present study, we constructed the artery stenosis model with ML and PL conditions. Porous medium modeling was used for analyzing biomass transport phenomena across within biological tissues, and we study the impact of microcirculation load on the pressure and flow field and hence the diagnosis parameter FFR of the artery stenosis model. It can be demonstrated that the downstream microvascular impedance of porous media which represents the flow resistance imposed by microcirculation, plays a dominant role compared with the stenosis local resistance. And the results showed that microcirculation load has significant effect on the coronary artery FFR measurement.

\section{The impact of microcirculation on blood hemodynamics}

In this study, the fluctuation range of the pressures in the ML model was larger than in the PL model, which is more prone to a physiological fact. The results show that in coronary stenotic artery model the microvascular system seems to have an essential role in regulating blood pressure. In normal arterial structure, microvessels usually supply most of the resistance to blood flow so that the pressure wave propagation is impeded and the reflection is produced [24]. The constitutive equation of microcirculation load has a decisive influence on various phenomena in the flow field. During systole period, blood which is not discharged in time is stored in the elastic artery. After entering the diastole period, the fluid stored will gradually flow out of the artery. Microcirculation is very important in circulation and serves a function to reallocate blood flow from a time scale. Therefore, in hemodynamic numerical simulation study, the influence of microcirculation load must be considered.

\section{The impact of microcirculation on FFR}

FFR is a well-validated clinical parameter derived from the measurement of coronary pressures and has greatly changed revascularization decision in clinical practice worldwide [25]. And now FFR is regarded as a goldstandard test for myocardial ischemia. Although FFRguided percutaneous coronary intervention (PCI) in stable CAD could reduce the rate of myocardial infarction or urgent revascularization, there is a debate on whether FFR-guided PCI in stable CAD could reduce the rate of all-cause mortality. The recent Parikh's study showed that the FFR-guided PCI reduce the the mortality compared with angiography-only guided PCI at 1 year follow-up [26]. However, after the 2 year follow-up, the FFR-guided PCI plus optimal medical therapy versus optimal medical therapy study showed a limited power of FFR to identify stenosis that require revascularization to prevent adverse events [27], whereas stenosis judged nonsignificant by FFR are still prone to adverse cardiac events. And another meta-analysis included individual patient data of three available randomized trials of contemporary FFR-guided PCI versus medical therapy for patients with stable coronary lesions and find that there
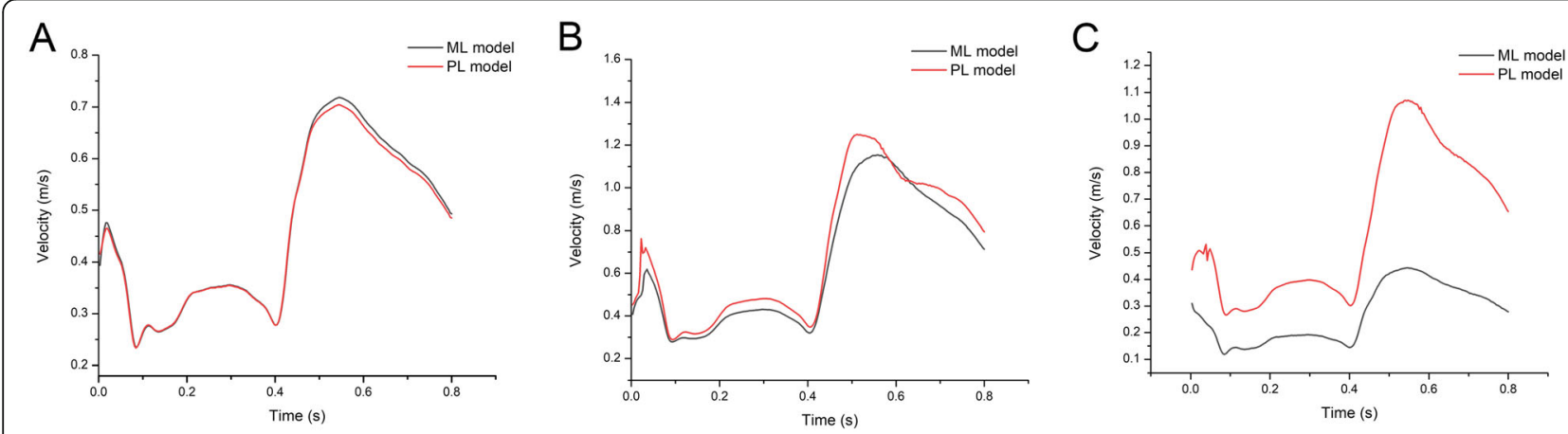

Fig. 4 Velocity profiles in the artery zone. a Velocity profiles in the Pre-stenotic domain. b Velocity profiles in the Post-stenotic domain. $\mathbf{c}$ Velocity profiles in the microcirculation domain 
was little evidence for a difference between groups in cardiac or all-cause deaths [28].

It should be noted that FFR is determined under the hypothesis of minimal and absolute stable microvascular resistance. The intravenous administration of adenosine is assumed to lead to a minimal and stable magnitude of coronary resistance in most patients. However, it is likely unattainable in the clinical practice. Microvascular resistance is unstable and variable even at maximal vasodilation condition [29]. The vasodilation mediator adenosine is far from able to abolish all vasoconstrictor tone [30]. In reality, adenosine only abolishes part of the coronary vasomotor tone in the individual patient. So it is speculated that the microcirculation coundn't be neglected in the simulation of coronary artery hemodynamics.

Coronary autoregulation is a multifactorial and complex process regulated by many mediators. And the functional loss of microcirculation will cause functional stenosis. A specific constant pressure profile is usually imposed at the outlet in traditional computational hemodynamics simulation. However, free outlet and constant load outlet do not meet the physiological requirements, and microcirculation load outlet condition can better simulate the physiology situation. In our study, the porous media of the microcirculation is shown to play an important role in the FFR calculation.

\section{The structure and function of microcirculation}

Coronary microvascular networks play a key role in determining blood flow in the heart. Alterations in the coronary microvasculature may exclusively determine the development of myocardial ischaemia [31]. Nellis et al. demonstrated that arteriolar and venular vessels smaller than $140 \mu \mathrm{m}$ in diameter contributed $70 \%$ of coronary vascular resistance in the ventricle. And Chilian et al. study the left ventricle and found that more than $50 \%$ of total coronary resistance arterioles less than $150 \mu \mathrm{m}$ in diameter [32].

As an important part of the arterial circulation, microvasculature plays important roles in many aspects, such as interstitial fluid generation, substance exchange and inverse flow. And the flow fields in the microcirculation zone may determine these processes. In this study, microvasculature is treated as a porous medium. When the porosity of the microcirculation zone are changed, the flow fields would be disturbed. Many disease such as diabetes, hypertension and hyperlipemia may lead to such microcirculation porosity changes. Study the hemodynamic changes induced by the pathological conditions may help us develop drugs treatment strategies (such as ACEI) which improved the microcirculation.

\section{Study limitations and future directions}

The present study has several limitations. Firstly, an ideal cylinder model was constructed rather than the patient-specific case. Clinically, the artery of the patient may be bifurcated and highly tortuous, and the haemodynamic research of that may show different outcomes. In addition, there is a fluid-structure interaction (FSI) and a seepage boundary condition between blood and arterial wall. This study didn't included the FSI effect. Thus in future work, a more severe case may be constructed included FSI study in association with the model using a seepage boundary condition. Thirdly, factors that influence the hemodynamic parameters such as vessel bending due to heart motion, lesion curvature and wall roughness were not included in this study. Using the data from the clinical and further experimental study would validate the computational results in the future as well.

\section{Conclusions}

Myocardial ischaemia may be caused by irregularities of both epicardial arteries and downstream microvascular networks. It was found that FFR value was slightly decreased with the presence of microcirculation load.

\section{Abbreviations}

FFR: Fractional flow reserve; CFD: Computational fluid dynamics; CAD: Coronary artery disease; PCl: Percutaneous coronary intervention; ML: Microcirculation load; PL: Pressure load; FSI: Fluid-structure interaction; AS: Area stenosis; Pa: Pressure at the aortic stenosis; Pd: Pressure distal to the coronary stenosis

\section{Acknowledgements}

The authors would like to thank Dr. Chunlin Zhao for his excellent help with the construction vascular geometrical model.

\section{Availability of data and material}

All data generated or analyzed during this study are included in this published article.

\section{Authors' contributions}

HZX and YZJ participated in the design, coordination, and interpretation of this study. $H Z X, J L$ and $D H Z$ did the CFD numerical modeling experiments. $H Z X$ and $J L$ wrote this manuscript. All authors read and approved the final manuscript.

\section{Funding}

None.

Ethics approval and consent to participate

The study was an numerical simulation study and needn't ethics approval..

\section{Consent for publication}

Not applicable.

\section{Competing interests}

The authors declare that they have no competing interests.

Received: 22 December 2019 Accepted: 13 March 2020

Published online: 21 March 2020

\section{References}

1. Goodwill AG, Dick GM, Kiel AM, Tune JD. Regulation of coronary blood flow. Comprehensive Physiology. 2017;7(2):321-82.

2. Garcia D, Harbaoui B, van de Hoef TP, Meuwissen M, Nijjer SS, EchavarriaPinto M, Davies JE, Piek JJ, Lantelme P. Relationship between FFR, CFR and coronary microvascular resistance - practical implications for FFR-guided percutaneous coronary intervention. PLoS One. 2019;14(1):e0208612. 
3. Murai T, Lee T, Yonetsu T, Isobe M, Kakuta T. Influence of microvascular resistance on fractional flow reserve after successful percutaneous coronary intervention. Cathet Cardiovasc Interv : Official J Soc Cardiac Angiography Interv. 2015;85(4):585-92.

4. Titterington JS, Hung OY, Wenger NK. Microvascular angina: an update on diagnosis and treatment. Futur Cardiol. 2015;11(2):229-42.

5. van de Hoef TP, Nolte F, Echavarrla-Pinto M, van Lavieren MA, Damman P, Chamuleau SA, Voskuil M, Verberne HJ, Henriques JP, van Eck-Smit BL, et al. Impact of hyperaemic microvascular resistance on fractional flow reserve measurements in patients with stable coronary artery disease: insights from combined stenosis and microvascular resistance assessment. Heart. 2014; 100(12):951-9

6. Yong AS, Ho M, Shah MG, Ng MK, Fearon WF. Coronary microcirculatory resistance is independent of epicardial stenosis. Circ Cardiovasc Interv. 2012; 5(1):103-8 S101-102.

7. Aarnoudse W, Fearon WF, Manoharan G, Geven M, van de Vosse F, Rutten M, De Bruyne B, Pijls NH. Epicardial stenosis severity does not affect minimal microcirculatory resistance. Circulation. 2004;110(15):2137-42.

8. Li B, Li X. A liquid-solid coupling hemodynamic model with microcirculation load. Appl Sci. 2016;6(1):28

9. Meuwissen M, Chamuleau SA, Siebes M, Schotborgh CE, Koch KT, de Winter RJ, Bax M, de Jong A, Spaan JA, Piek JJ. Role of variability in microvascular resistance on fractional flow reserve and coronary blood flow velocity reserve in intermediate coronary lesions. Circulation. 2001;103(2):184-7.

10. Giacinta G, Paola Giuseppina C, Alda H, Doralisa M, William MC, Mario M. Microvascular function/dysfunction downstream a coronary stenosis. Curr Pharm Des. 2013;19(13):2366-74.

11. Chen X, Gao Y, Lu B, Jia X, Zhong L, Kassab GS, Tan W, Huo Y. Hemodynamics in coronary arterial tree of serial Stenoses. PLoS One. 2016; 11(9):e0163715

12. Coccarelli A, Prakash A, Nithiarasu P. A novel porous media-based approach to outflow boundary resistances of $1 \mathrm{D}$ arterial blood flow models. Biomech Model Mechanobiol. 2019;18(4):939-51.

13. Debbaut C, Vierendeels J, Casteleyn C, Cornillie P, Van Loo D, Simoens P, Van Hoorebeke L, Monbaliu D, Segers P. Perfusion characteristics of the human hepatic microcirculation based on three-dimensional reconstructions and computational fluid dynamic analysis. J Biomech Eng. 2012:134(1):011003.

14. Soltani $M$, Chen P. Numerical modeling of interstitial fluid flow coupled with blood flow through a remodeled solid tumor microvascular network. PLoS One. 2013;8(6):e67025

15. Khaled ARA, Vafai $K$. The role of porous media in modeling flow and heat transfer in biological tissues. Int J Heat Mass Transf. 2003;46(26):4989-5003.

16. Elhanafy A, Guaily A, Elsaid A. Numerical simulation of blood flow in abdominal aortic aneurysms: Effects of blood shear-thinning and viscoelastic properties. Math Comput Simul. 2019;160:55-71.

17. Doutel E, Pinto SI, Campos JB, Miranda JM. Link between deviations from Murray's law and occurrence of low wall shear stress regions in the left coronary artery. J Theor Biol. 2016:402:89-99.

18. He F, Hua L, L-j G. A hemodynamic model with a seepage condition and fluid-structure interactions for blood flow in arteries with symmetric stenosis. J Biol Phys. 2019;45(2):183-92.

19. Narayan O, Leung MC, Wong DT, Meredith IT, Cameron JD. Percutaneous coronary intervention enhances accelerative wave intensity in coronary arteries. PLoS One. 2015;10(12):e0142998.

20. Chilian WM, Layne SM, Klausner EC, Eastham CL, Marcus ML. Redistribution of coronary microvascular resistance produced by dipyridamole. Am J Phys. 1989;256(2 Pt 2):H383-90

21. Duncker DJ, Koller A, Merkus D, Canty JM Jr. Regulation of coronary blood flow in health and ischemic heart disease. Prog Cardiovasc Dis. 2015;57(5): 409-22.

22. Pijls NH, Sels JW. Functional measurement of coronary stenosis. J Am Coll Cardiol. 2012;59(12):1045-57.

23. Camici PG, d'Amati G, Rimoldi O. Coronary microvascular dysfunction: mechanisms and functional assessment. Nat Rev Cardiol. 2015;12(1):48-62.

24. He F, Hua L, Gao LJ. A seepage outlet boundary condition in hemodynamics modeling. Biom Technik Biomed Eng. 2017;62(5): 521-7.

25. Tonino PA, De Bruyne B, Pijls NH, Siebert U, Ikeno F, T Veer M V, Klauss V, Manoharan $\mathrm{G}$, Engstrom T, Oldroyd KG, et al. Fractional flow reserve versus angiography for guiding percutaneous coronary intervention. N Engl J Med. 2009:360(3):213-24

26. Parikh RV, Liu G, Plomondon ME, Sehested TSG, Hlatky MA, Waldo SW, Fearon WF. Utilization and outcomes of measuring fractional flow Reserve in Patients with Stable Ischemic Heart Disease. J Am Coll Cardiol. 2020;75(4): 409-19.

27. De Bruyne B, Fearon WF, Pijls NH, Barbato E, Tonino P, Piroth Z, Jagic N, Mobius-Winckler S, Rioufol G, Witt N, et al. Fractional flow reserve-guided PCI for stable coronary artery disease. N Engl J Med. 2014;371(13):1208-17.

28. Zimmermann FM, Omerovic E, Fournier S, Kelbaek H, Johnson NP, Rothenbuhler M, Xaplanteris P, Abdel-Wahab M, Barbato E, Hofsten DE, et al. Fractional flow reserve-guided percutaneous coronary intervention vs. medical therapy for patients with stable coronary lesions: meta-analysis of individual patient data. Eur Heart J. 2019;40(2):180-6.

29. van de Hoef TP, Meuwissen M, Piek JJ. Fractional flow reserve-guided percutaneous coronary intervention: where to after FAME 2? Vasc Health Risk Manag. 2015;11:613-22.

30. Heusch G. Adenosine and maximum coronary vasodilation in humans: myth and misconceptions in the assessment of coronary reserve. Basic Res Cardiol. 2010;105(1):1-5.

31. Camici PG, Crea F. Coronary microvascular dysfunction. N Engl J Med. 2007; 356(8):830-40.

32. Muller-Delp JM. The coronary microcirculation in health and disease. Isrn Physiology. 2013;2013(2):221-31.

\section{Publisher's Note}

Springer Nature remains neutral with regard to jurisdictional claims in published maps and institutional affiliations.
Ready to submit your research? Choose BMC and benefit from:

- fast, convenient online submission

- thorough peer review by experienced researchers in your field

- rapid publication on acceptance

- support for research data, including large and complex data types

- gold Open Access which fosters wider collaboration and increased citations

- maximum visibility for your research: over $100 \mathrm{M}$ website views per year

At $\mathrm{BMC}$, research is always in progress.

Learn more biomedcentral.com/submissions 